Military Technical College Kobry El-Kobbah, Cairo, Egypt

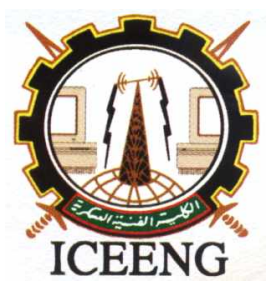

\author{
$6^{\text {th }}$ International Conference \\ on Electrical Engineering \\ ICEENG 2008
}

\title{
ENHANCING POWER SYSTEM PERFORMANCE THROUGH USING INJECTION POWER UPFC
}

$$
B y^{*}
$$

\author{
K. Abdel-Aty \\ khldon@hotmail.com
}

\author{
S. F. Mekhamer \\ sfmekhamer@yahoo.com
}

\author{
T. S. Abdel-Salam \\ tarekabdelsalam@gmail.com
}

\author{
M. M. Mansour \\ mmsmansour@ieee.org
}

\section{Abstract:}

This paper is devoted to the incorporation of the steady state model of the unified power flow controller (UPFC) in optimal power flow programs using injection model of UPFC. This model is based on the representation of UPFC in steady state conditions by two voltage sources with certain reactances. The effects of UPFC control parameters on generation cost, system voltage profile, and system loadability are studied. The proposed method has been applied to the IEEE 57-bus system with promising results.

Keywords: Optimal Power Flow- FACTS - UPFC-Voltage Profile-Loadability.

\section{Introduction:}

Flexible AC Transmission Systems (FACTS) represents a new domain in power system control engineering, using power electronic devices and circuits and the more recent available technologies in automatic control and valves [1]. With the application of FACTS technology, power system becomes more flexibly controlled [2]. It can be used to extend the capacity of existing power transmission networks to their limits without the necessity of adding new transmission lines [3]. 
So, FACTS can facilitate the power flow control, decrease the cost of generation, enhance the power transfer capability, and improve the security and stability of the power system [4]. The unified power flow controller (UPFC) is the most comprehensive multivariable flexible ac transmission system (FACTS) controller [5, 6]. It can provide simultaneous and independent control of power system parameters such as line active power flow, line reactive power flow, line impedances, and node voltages $[7,8]$. In this paper, the steady state model of the unified power flow controller (UPFC) using injection power model [9] is incorporated in a MATLAB optimal power flow programs. Using this model of UPFC the effects of UPFC control parameters on generation cost, system voltage profile, and system loadability are studied and illustrated. The proposed method has been investigated on the IEEE 57-bus system [10].

\section{Operating Principle of UPFC:}

UPFC (Fig. 1) consists of two switching converters. These converters are operated from a common dc link provided by a dc storage capacitor. Converter 2 provides the main function of the UPFC by injecting an ac voltage with controllable magnitude and phase angle in series with the transmission line via a series transformer [9]. The basic function of converter 1 is to supply or absorb the real power demand by converter 2 at the common dc link. It can also generate or absorb controllable reactive power and provide independent shunt reactive compensation for the line. Converter 2 supplies or absorbs locally the required reactive power and exchanges the active power as a result of the series injection voltage.

\section{Modeling of UPFC:}

A UPFC can be represented in steady-state conditions by two voltage sources representing fundamental components of output voltage waveforms of the two converters and impedances being the leakage reactances of the two coupling transformers. Fig. 2 depicts a two voltage-source model of the UPFC. The voltage sources, $\mathrm{V}_{\mathrm{ser}}$ and $\mathrm{V}_{\mathrm{sh}}$, are controllable in both magnitudes and phase angles.

$\mathrm{V}_{\text {ser }}$ should be defined as:

$\mathrm{V}_{\text {ser }}=r \mathrm{Vie}_{\mathrm{i}}^{\mathrm{j} \theta_{\text {ser }}}$

Where, $0 \leq \mathrm{r} \leq \mathrm{r}_{\max }$ and $0 \leq \theta_{\text {ser }} \leq 2 \pi$. 


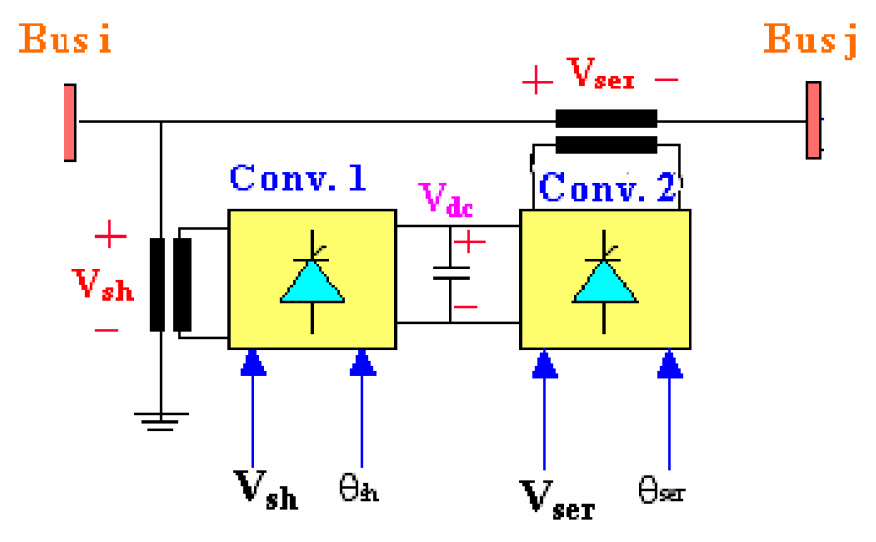

Figure (1): Basic circuit arrangement of UPFC

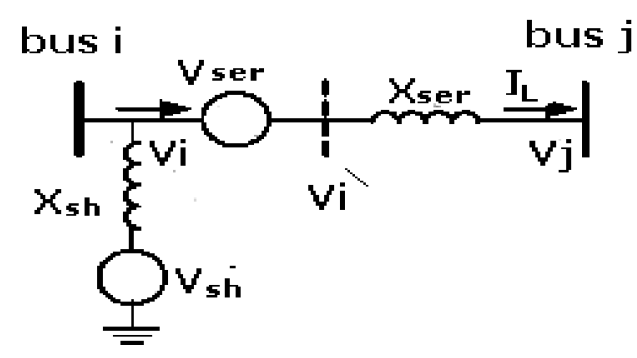

Figure (2): UPFC equivalent circuit

\subsection{Series Connected Voltage Source Converter Model}

The steady-state UPFC mathematical injection model is developed by replacing voltage source $V_{\text {ser }}$ by a current source $I_{\text {ser }}$ parallel with a susceptance $b_{\text {ser }}=1 / X_{\text {ser }}$. Therefore, the series current $I_{\text {ser }}$ is defined by:

$\mathrm{I}_{\mathrm{ser}}=-\mathrm{j} \mathrm{b}_{\mathrm{ser}} \mathrm{V}_{\mathrm{ser}}$

The current source $I_{\text {ser }}$ can be modeled by injected power at the two buses $i$ and $j$ between which the UPFC is connected as shown in Fig. 3.

$$
\begin{aligned}
& S_{\text {iser }}=V_{i}\left(-I_{\text {ser }}\right)^{*} \\
& S_{\text {ser }}=V_{j}\left(I_{\text {ser }}\right)^{*}
\end{aligned}
$$




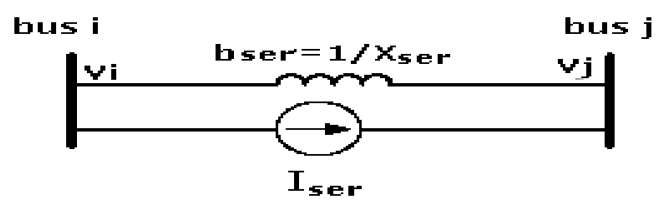

Figure (3): Replacement of series voltage source by a current source

The injected powers $S_{\text {iser }}$ and $S_{\text {sser }}$ can be simplified according to the following operations, by substituting equations (1) and (3) into (4) and (5). The power injected at bus $i$ is found by substituting equations (1) and (3) into (4) to yield:

$S_{\text {iser }}=V_{i}\left(j b_{\text {serr }} r V_{i} e^{j \theta \text { ser }}\right)^{*}$

By using the Euler Identity, $\left(\mathrm{e}^{\mathrm{j} \theta_{\mathrm{ser}}}=\cos \theta_{\mathrm{ser}}+\mathrm{j} \sin \theta_{\text {ser }}\right)$, and trigonometric identities equation (6) takes the form:

$S_{\text {iser }}=\mathrm{V}_{\mathrm{i}}^{2} b_{\text {serr }}\left[\cos \left(-\theta_{\text {ser }}-90\right)+\mathrm{j} \sin \left(-\theta_{\text {ser }}-90\right)\right]$.

Equation (7) can be decomposed into its real and imaginary components, $\mathrm{S}_{\text {iser }}=\mathrm{P}_{\text {iser }}+\mathrm{j} \mathrm{Q}_{\text {iser }}$ where,

$\mathrm{P}_{\text {iser }}=-\mathrm{rb}_{\text {ser }} \mathrm{V}_{\mathrm{i}}^{2} \sin \theta_{\text {ser }}$

$\mathrm{Q}_{\text {iser }}=-\mathrm{rb} \mathrm{ser}_{\mathrm{i}} \mathrm{V}^{2} \cos \theta_{\text {ser }}$

Similarly the power injected at bus $\mathrm{j}$ is obtained by substituting equations (1) and (3) into (5) to yield:

$S_{\text {ser }}=\mathrm{V}_{\mathrm{i}} \mathrm{V}_{\mathrm{j}} \mathrm{b}_{\mathrm{ser}} \mathrm{sin}\left(\delta_{\mathrm{i}}-\delta_{\mathrm{j}}+\theta_{\mathrm{ser}}\right)+\mathrm{j} \mathrm{V}_{\mathrm{i}} \mathrm{V}_{\mathrm{j}} \mathrm{b}_{\mathrm{ser}} \mathrm{cos}\left(\delta_{\mathrm{i}}-\delta_{\mathrm{j}}-\theta_{\text {ser }}\right)$

Equation (10) can also be decomposed into its real and imaginary parts, $\mathrm{S}_{\mathrm{jser}}=\mathrm{P}_{\mathrm{jser}}+\mathrm{j} \mathrm{Q}_{\mathrm{jser}}$, with:

$\mathrm{P}_{\mathrm{jser}}=\mathrm{V}_{\mathrm{i}} \mathrm{V}_{\mathrm{j}} \mathrm{b}_{\mathrm{ser}} \mathrm{s} \sin \left(\delta_{\mathrm{i}}-\delta_{\mathrm{j}}-\theta_{\mathrm{ser}}\right)$

$\mathrm{Q}_{\mathrm{jser}}=\mathrm{V}_{\mathrm{i}} \mathrm{V}_{\mathrm{j}} \mathrm{b}_{\mathrm{ser}} \cos \left(\delta_{\mathrm{i}}-\delta_{\mathrm{j}}-\theta_{\text {ser }}\right)$ 
Based on equations (8), (9), (11), and (12), the power injection model of the series connected voltage source can be seen as two dependent power injections at auxiliary buses $i$ and j, as shown in Fig. 4.

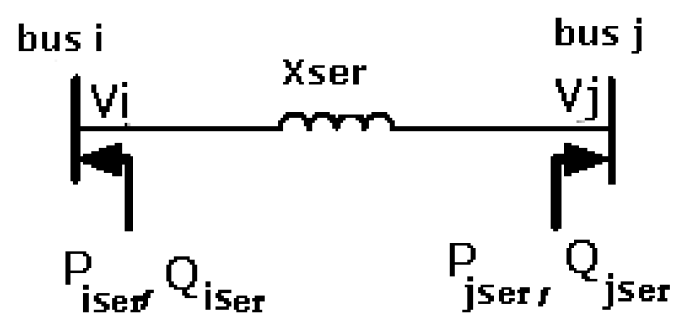

Equivalent power injection of series branch at bus $\mathbf{i}$

Equivalent power injection of series branch at bus $\mathrm{j}$

Figure (4): Equivalent power injections of series branch

\subsection{Shunt Connected Voltage Source Converter Model}

In UPFC, the shunt branch is used mainly to provide both the real power, $\mathrm{P}_{\text {ser }}$, which is injected to the system through the series branch, and the total losses within the UPFC. If the losses are to be neglected in the real power injection of the shunt connected voltage source at bus $\mathrm{i}, \mathrm{P}_{\mathrm{sh}}$ is equal to the injected series real power $\mathrm{P}_{\text {ser }}$ through the series connected voltage source to the system. This can be expressed by:

$\mathrm{P}_{\mathrm{ser}}+\mathrm{P}_{\mathrm{sh}}=0$

The apparent power supplied by the series converter is calculated as.

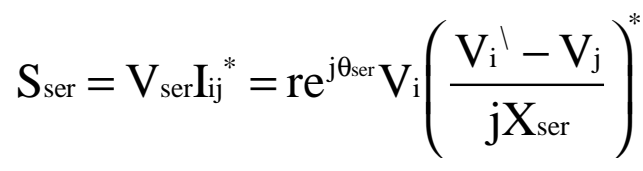

Active and reactive power supplied by the series converter can be calculated from equation (14):

$S_{\text {ser }}=r e^{j \theta_{\text {ser }}} V_{i}\left(\left(r e^{j \theta_{\text {ser }}} V_{i}+V_{i}-V_{j}\right) / j X_{\text {ser }}\right)^{*}$ 


$$
\begin{aligned}
S_{\text {ser }}= & j b_{\text {serr }}{ }^{2} V_{i}^{2}+j b_{\text {serr }} V_{i}^{2}\left(\cos \theta_{\text {ser }}+j \sin \theta_{\text {ser }}\right)-j b_{s e r} V_{i} V_{j}\left(\cos \left(\delta_{i}-\delta_{j}+\theta_{\text {ser }}\right)\right. \\
& \left.+j \sin \left(\delta_{i}-\delta_{j}+\theta_{\text {ser }}\right)\right)
\end{aligned}
$$

The final form of equation (16) can be written as:

$$
\begin{aligned}
& S_{\text {ser }}=P_{\text {ser }}+j Q_{\text {ser }}, \text { where } \\
& P_{\text {ser }}=r b_{s e r} V_{i} V_{j} \sin \left(\delta_{i}-\delta_{j}+\theta_{\text {ser }}\right)-r b_{\text {ser }} V_{i}^{2} \sin \theta_{\text {ser }} \\
& Q_{\text {ser }}=-r b_{\text {ser }} V_{i} V_{j} \cos \left(\delta_{i}-\delta_{j}+\theta_{\text {ser }}\right)+r b_{\text {ser }} V_{i}^{2} \cos \theta_{\text {ser }}+r^{2} b_{\text {ser }} V_{i}^{2}
\end{aligned}
$$

The reactive power delivered or absorbed by the shunt converter is independently controllable by the UPFC and can be modeled as a separate controllable shunt reactive source. In this case the main function of reactive power is to maintain the voltage levels at bus i within acceptable limits. Consequently, steady-state UPFC mathematical model is constructed from the series connected voltage source model with the addition of a power injection equivalent to $P_{s h}+j Q_{s h}$ to bus $i$, as shown in Fig. 5. Where:

$$
\mathrm{P}_{\mathrm{sh}}=-\mathrm{P}_{\mathrm{ser}}=-\mathrm{rb} \mathrm{ber}_{\operatorname{ser}} \mathrm{V}_{\mathrm{i}} \mathrm{V}_{\mathrm{j}} \sin \left(\delta_{\mathrm{i}}-\delta_{\mathrm{j}}+\theta_{\text {ser }}\right)+\mathrm{rb}_{\text {ser }} \mathrm{V}_{\mathrm{i}}^{2} \sin \theta_{\text {ser }}
$$

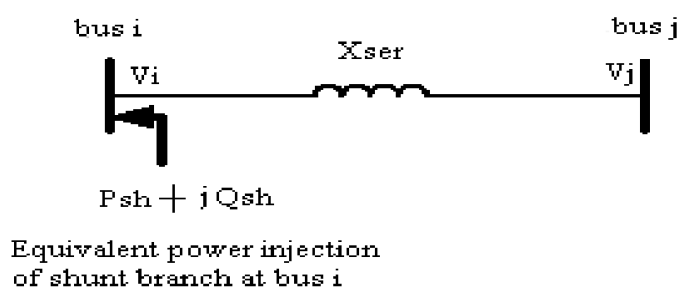

Figure (5): Equivalent power injection of shunt branch

\subsection{Whole UPFC Injection Model}

Finally, steady-state UPFC mathematical model can be constructed by combining the series and shunt power injections at both bus $i$ and bus $j$ as shown in Fig. 6. 


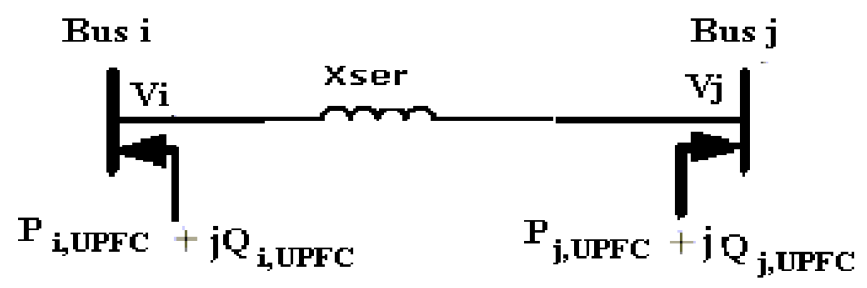

Figure (6): Steady-state UPFC mathematical model

Having $\delta_{\mathrm{ij}}=\delta_{\mathrm{i}}-\delta_{\mathrm{j}}$, the elements of the equivalent power injections in Fig. (6) are,

$P_{i, \text { UPFC }}=P_{\text {iser }}+P_{\text {sh }}=-r b_{\text {ser }} V_{i} V_{j} \sin \left(\delta_{i j}+\theta_{\text {ser }}\right)$

$\mathrm{P}_{\mathrm{j}, \mathrm{UPFC}}=\mathrm{P}_{\mathrm{jser}}=\mathrm{rb} \mathrm{b}_{\mathrm{ser}} \mathrm{V}_{\mathrm{i}} \mathrm{V}_{\mathrm{j}} \sin \left(\delta_{\mathrm{ij}}+\theta_{\text {ser }}\right)$

$\mathrm{Q}_{\mathrm{i}, \mathrm{UPFC}}=\mathrm{Q}_{\mathrm{iser}}+\mathrm{Q}_{\mathrm{sh}}=-\mathrm{rb} \mathrm{ser}_{\mathrm{ser}} \mathrm{V}_{\mathrm{i}}^{2} \cos \theta_{\text {ser }}+\mathrm{Q}_{\mathrm{sh}}$

$\mathrm{Q}_{\mathrm{j}, \mathrm{UPFC}}=\mathrm{Q}_{\mathrm{jser}}=\mathrm{rb}_{\mathrm{ser}} \mathrm{V}_{\mathrm{i}} \mathrm{V}_{\mathrm{j}} \cos \left(\delta_{\mathrm{ij}}+\theta_{\mathrm{ser}}\right)$

\section{UPFC Injection Model for Optimal Power Flow Studies}

The UPFC injection model can easily be incorporated in optimal power flow program as follows:

\subsection{Modification of Admittance Matrix:}

If a UPFC is located between bus $i$ and bus $j$ in a power system, the admittance matrix is modified by adding the reactance $\mathrm{X}_{\text {ser }}$ between buses $\mathrm{i}$ and $\mathrm{j}$.

\subsection{Modification of Jacobian Matrix:}

The Jacobian matrix is modified by addition of appropriate injection powers at buses $\mathrm{i}$ and $\mathrm{j}$ according to equations (20) to (23), considering the linearized load flow model as:

$\left[\begin{array}{c}\Delta \mathrm{P} \\ \Delta \mathrm{Q}\end{array}\right]^{\mathrm{n}}=\left[\begin{array}{ll}\mathrm{H} & \mathrm{N} \\ \mathrm{J} & \mathrm{L}\end{array}\right]^{\mathrm{n}}\left[\begin{array}{l}\Delta \delta \\ \Delta \mathrm{V} / \mathrm{V}\end{array}\right]^{\mathrm{n}}$, 
Where $\Delta \mathrm{P}$ and $\Delta \mathrm{Q}$ are the real power and reactive power mismatch vectors. $(\Delta \mathrm{V}$ and $\Delta \boldsymbol{\delta}$ ) are vectors of incremental changes in nodal voltages and angles. H, N, J, and $\mathrm{L}$ denote the basic elements in the Jacobian matrix. $\mathrm{n}$ is iteration number. Since injected powers vary with bus voltage amplitudes and phases, the relevant elements of Jacobian matrix will be modified at each iteration. Based on Equations (20) and (23), the following additional elements of Jacobian matrix $\left(\left(\mathrm{H}=\mathrm{H}^{\circ}+\mathrm{H}^{\mathrm{UPF}}\right)\right.$ and for $\mathrm{N}, \mathrm{J}$, and $\mathrm{L}$ elements) owing to the injections of the UPFC at the buses $i$ and $j$ can be derived. The superscript o denotes the Jacobian elements without UPFC.

\subsection{Modification of the Mismatch Equations:}

The related power mismatch equations at bus $\mathrm{i}$ and bus $\mathrm{j}$ must be modified as:

$$
\begin{aligned}
& \Delta \mathrm{P}_{\mathrm{i}}=\mathrm{P}_{\mathrm{i}, \mathrm{G}}-\mathrm{P}_{\mathrm{i}, \mathrm{L}}+\mathrm{P}_{\mathrm{i}, \mathrm{UPFC}}-\mathrm{P}_{\mathrm{i}, \mathrm{Cal}} \\
& \Delta P_{j}=P_{j, G}-P_{j, L}+P_{j, ~ U P F C}-P_{j, C a l} \\
& \Delta \mathrm{Q}_{\mathrm{i}}=\mathrm{Q}_{\mathrm{i}, \mathrm{G}}-\mathrm{Q}_{\mathrm{i}, \mathrm{L}}+\mathrm{Q}_{\mathrm{i}, \mathrm{UPFC}}-\mathrm{Q}_{\mathrm{i}, \mathrm{Cal}} \\
& \Delta \mathrm{Q}_{\mathrm{j}}=\mathrm{Q}_{\mathrm{j}, \mathrm{G}}-\mathrm{Q}_{\mathrm{j}, \mathrm{L}}+\mathrm{Q}_{\mathrm{j}, \mathrm{UPFC}}-\mathrm{Q}_{\mathrm{j}, \mathrm{Cal}}
\end{aligned}
$$

\section{Effects of UPFC Control Parameters on Power System Operation:}

To investigate the effect of UPFC control parameters ( $r, \theta_{\text {ser }}$ and $\left.\mathrm{Q}_{\text {sh }}\right)$ on the operation of the IEEE 57-bus system (baseMVA = 100), A UPFC is assumed to be located between buses 31 and 32, near bus 31 (the weakest bus), and the effect of these parameters on generation cost, system voltage profile, and system loadability are studied.

\subsection{Effects of UPFC Control Parameters on Generation Cost:}

Fig. 7 shows the effect of varying $r\left(\theta_{\text {ser }}=10^{\circ}, Q_{\text {sh }}=0.1 \mathrm{pu}\right)$ on the cost of generation. The results show that $r=0.09$ pu gives the minimum cost of generation $(41728 \$ / \mathrm{h})$ due to the losses reduction. Note that, the cost without UPFC was 41738 \$/h. Also, the effects of varying $\theta_{\text {ser }}$ and $Q_{\text {sh }}$ on the generation cost are shown in Fig. 8 and Fig. 9 respectively. It can be concluded that the cost of generation can be minimized by adjusting the three control parameters of UPFC. 


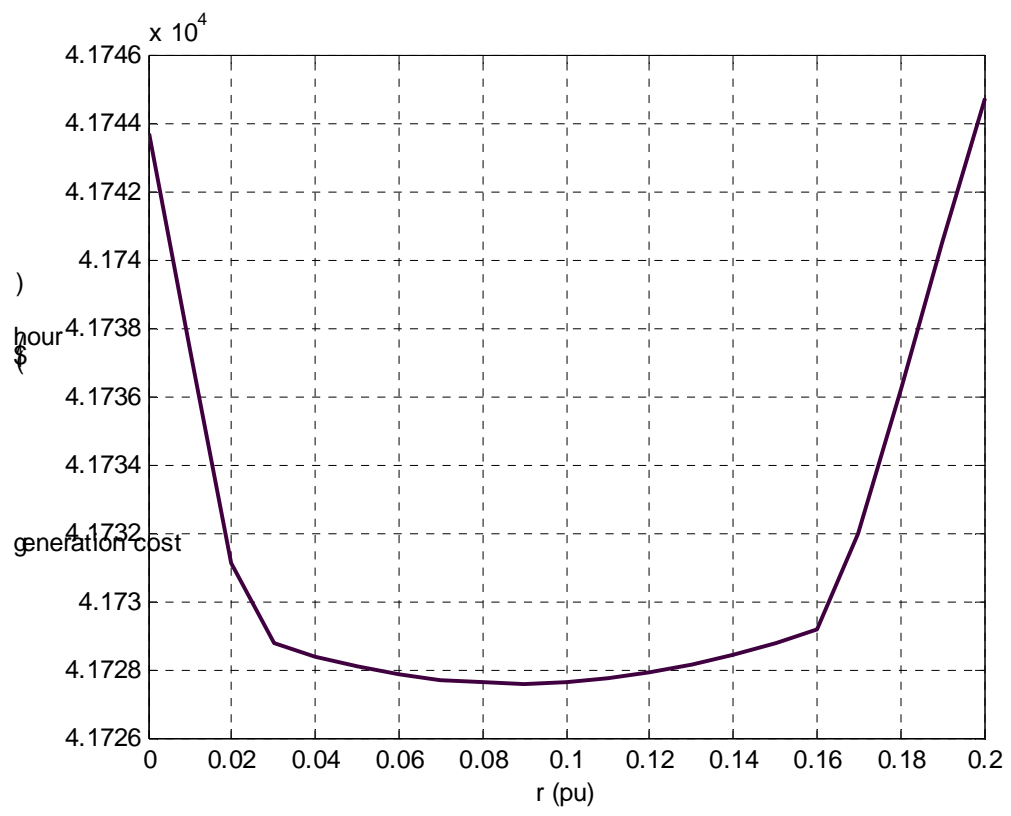

Figure (7): Effect of varying $r$ on generation $\operatorname{cost}\left(\theta_{\mathrm{ser}}=10^{\circ}, Q \operatorname{sh}=0.1 \mathrm{pu}\right)$

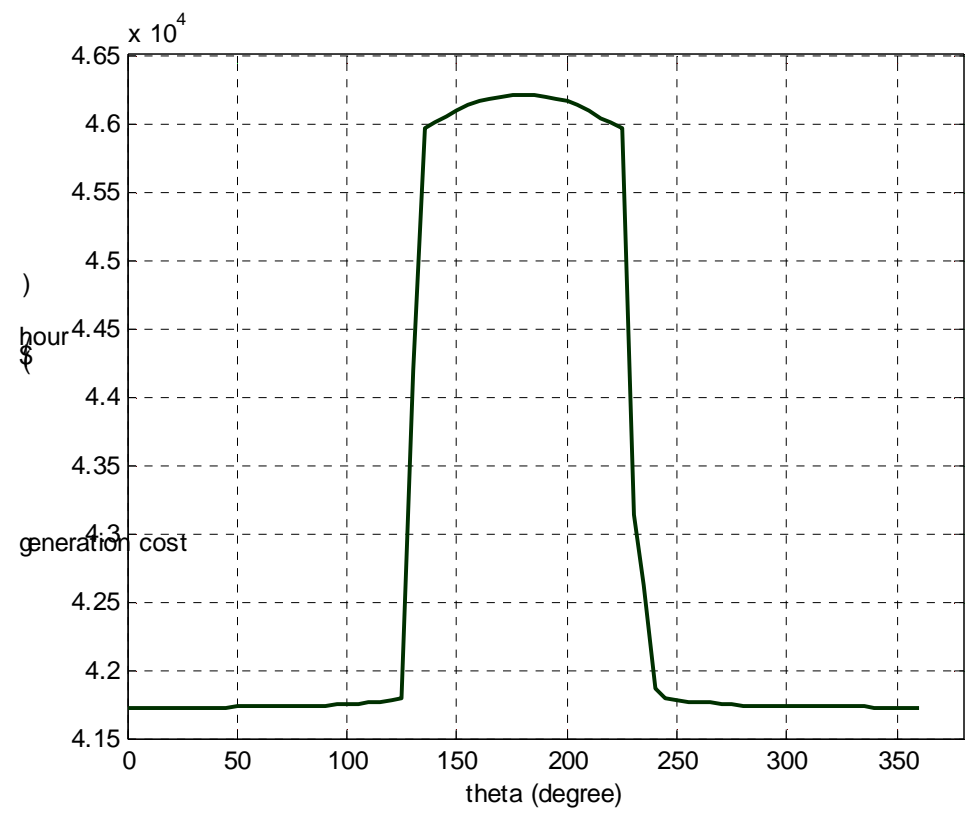

Figure (8): Effect of varying $\theta_{\mathrm{ser}}$ on generation cost $(r=0.1 \mathrm{pu}, Q \mathrm{sh}=0.1)$ 


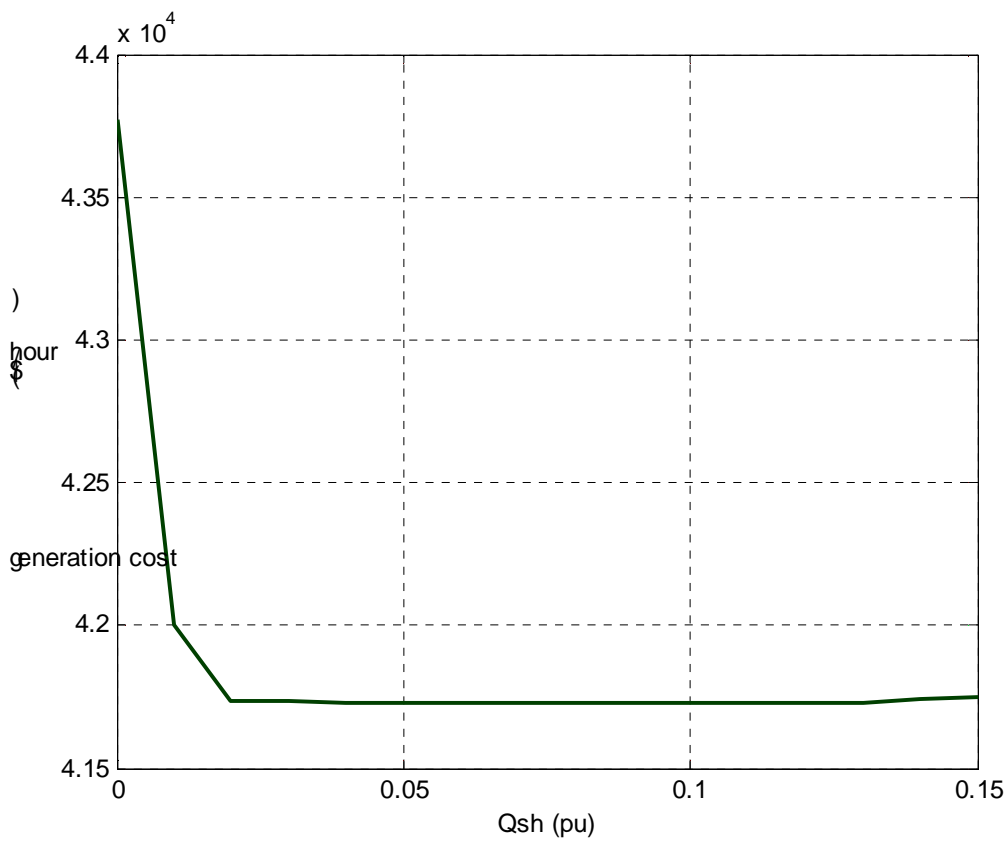

Figure (9): Effect of varying $Q_{\text {sh }}$ on generation cost $\left(r=0.1 \mathrm{pu}, \theta_{\mathrm{ser}}=10^{\circ}\right)$

\subsection{Effects of UPFC Control Parameters on System Voltage Profile:}

Previous objective function (generation cost) seeks to improve the cost of operation regardless of the power quality. Optimal power system operation requires some kind of compromise between the operation cost and quality. Voltage Profile Index (VPI) is one of the quality measures for power system. It can be improved by minimizing the load bus voltage deviations from $1.0 \mathrm{pu}$. The objective function can be expressed as:

$\mathrm{VPI}=\operatorname{Sum}|\mathrm{V}-1|$

Figures 10, 11, and 12 show the effect of $r, \theta_{\text {ser }}$ and $Q_{\text {sh }}$ respectively on the system voltage profile. From these Figures, it is clear that the voltage profile can be enhanced by controlling the control parameter of UPFC. That the voltage profile reaches to 1.1208 when $\mathrm{r}=0.19 \mathrm{pu}, \theta_{\text {ser }}=10^{\circ}$, and $\mathrm{Q}_{\text {sh }}=0.1 \mathrm{pu}$. Knowing that the system voltage profile without UPFC is equal to 1.3057 . 


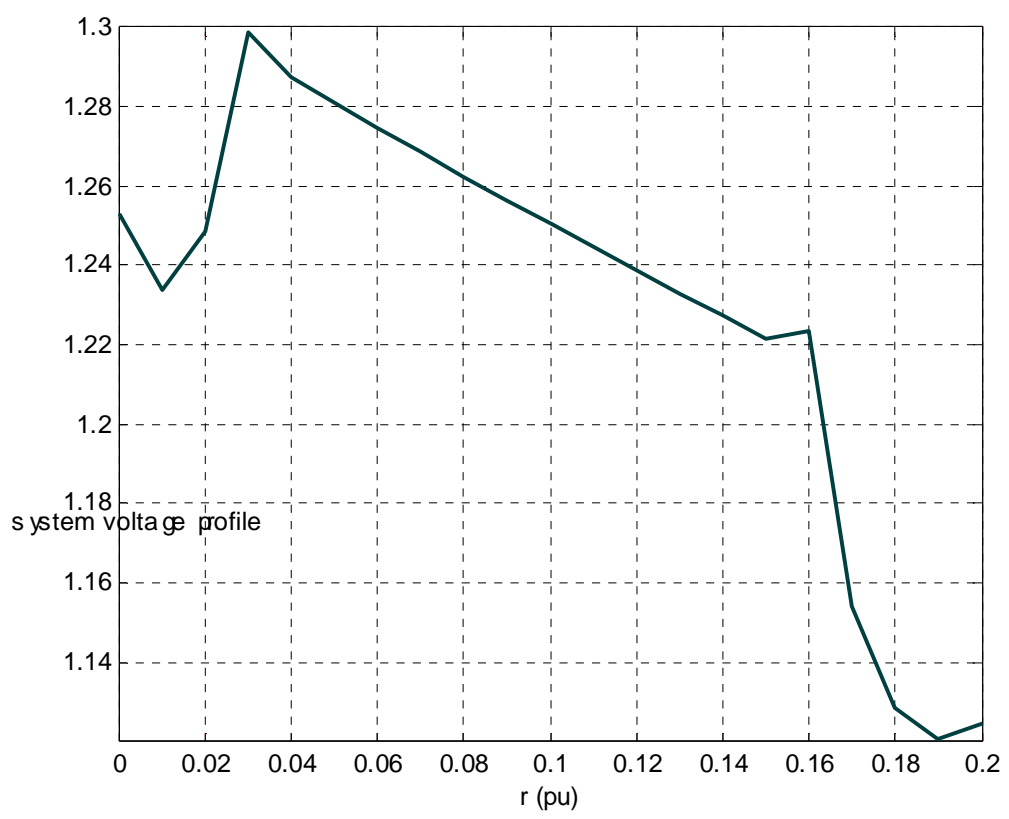

Figure (10): Effect of varying $r$ on system voltage profile $\left(\theta_{\mathrm{ser}}=10^{\circ}, Q \mathrm{sh}=0.1 \mathrm{pu}\right)$

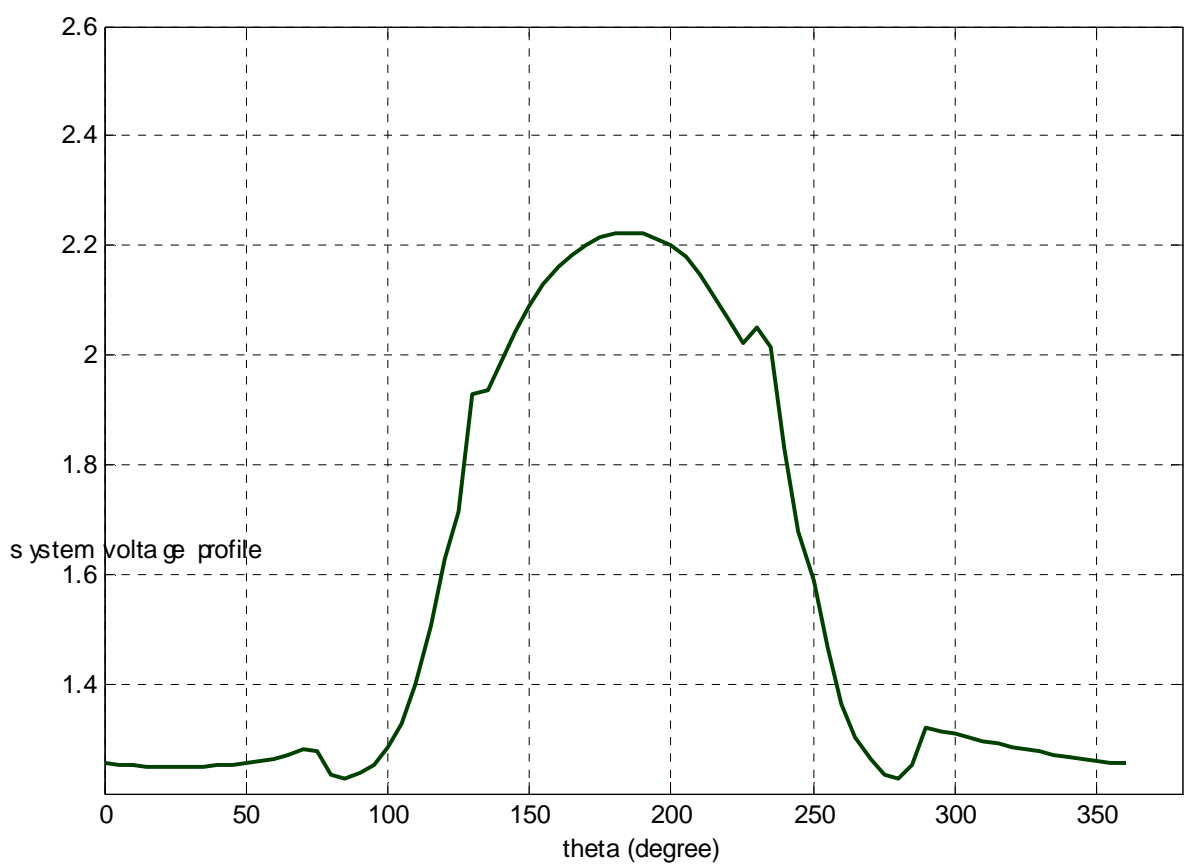

Figure (11): Effect of varying $\theta_{\text {ser }}$ on system voltage profile( $\left.r=0.1 \mathrm{pu}, Q s h=0.1\right)$ 


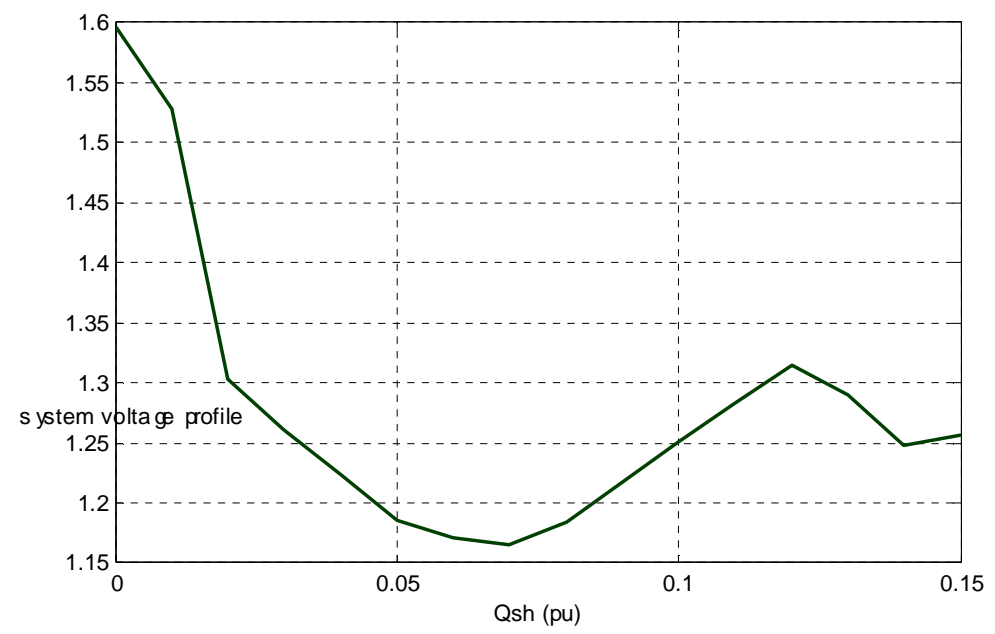

Figure (12): Effect of varying $Q_{\text {sh }}$ on system voltage profile $\left(r=0.1 \mathrm{pu}, \theta_{\mathrm{ser}}=10^{\circ}\right)$

\subsection{Effects of UPFC Control Parameters on System Loadability:}

Another power quality measure is the system loadabilty. The system loadability can be measured by the Loadability Factor (LF), which defined as:

$\mathrm{LF}=\operatorname{Sum}\left(\left|\mathrm{S} / \mathrm{S}_{\max }\right|^{\wedge} 2\right)$

To enhance the system loadability this factor must be minimized. The results of varying the various control parameters of UPFC to enhance the system loadability are shown in Figures 13, 14, and 15.

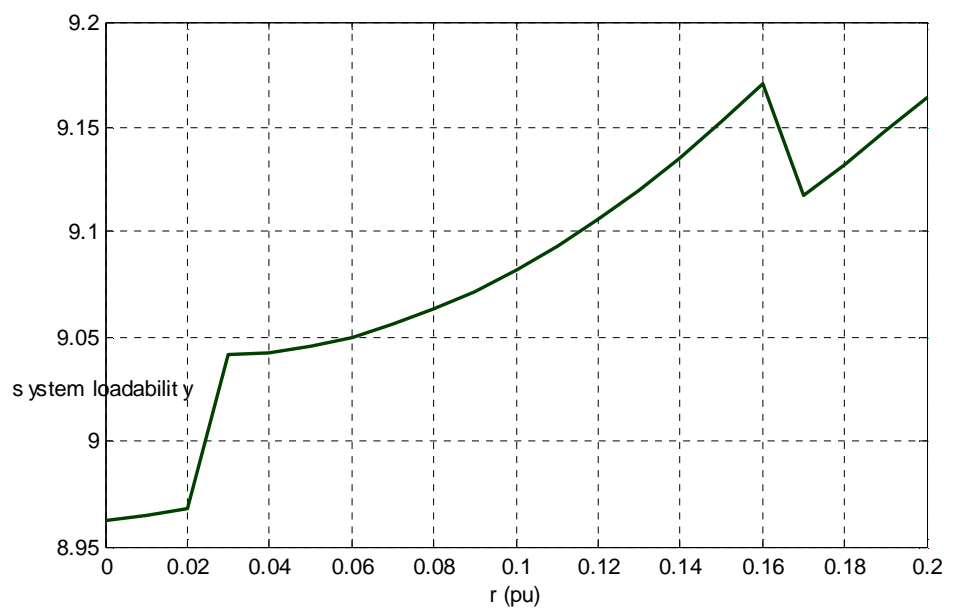

Figure (13): Effect of varying $r$ on system loadabilty $\left(\theta_{\mathrm{ser}}=10^{\circ}, Q \mathrm{sh}=0.1 \mathrm{pu}\right)$ 


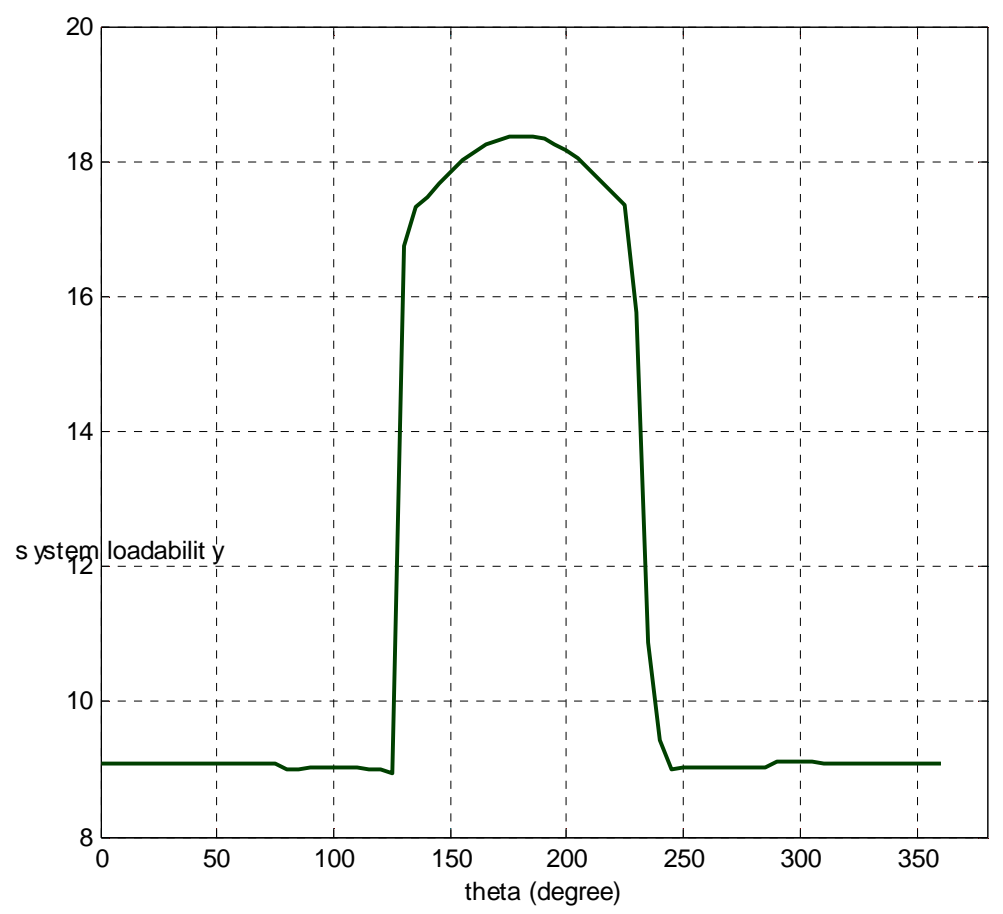

Figure (14): Effect of varying $\theta_{\mathrm{ser}}$ on system loadability $(r=0.1 \mathrm{pu}, Q \mathrm{sh}=0.1)$

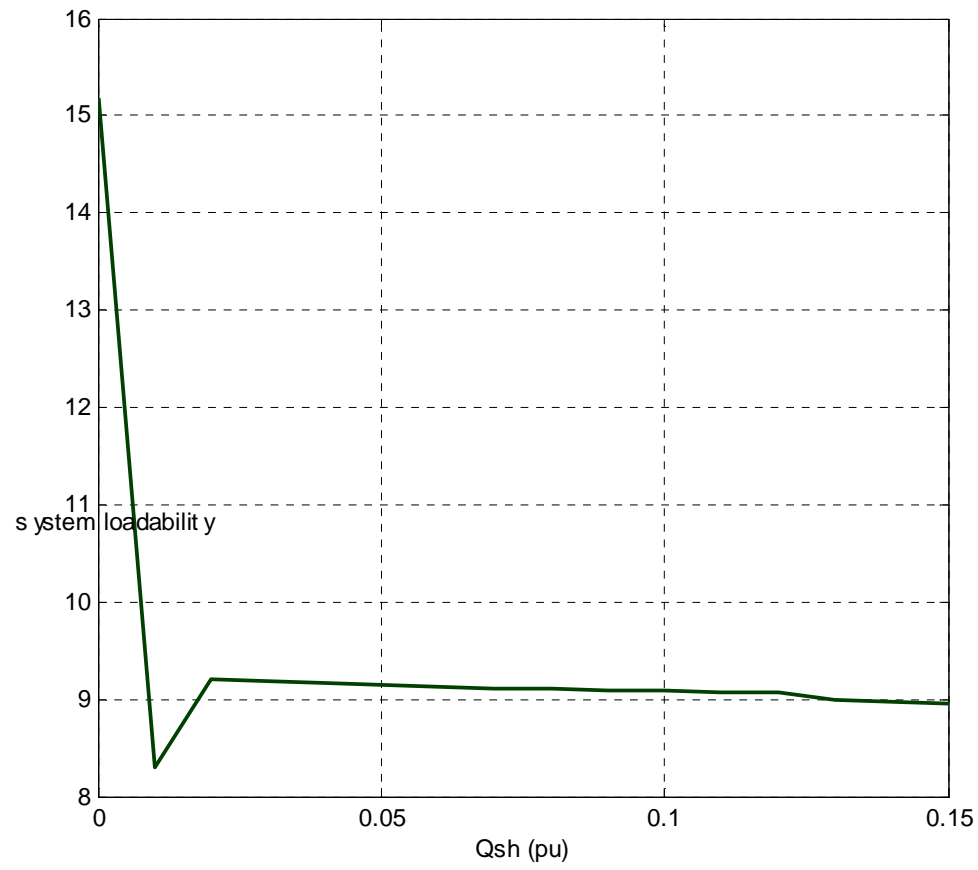

Figure (15): Effect of varying $Q_{\text {sh }}$ on system loadability $\left(r=0.1 \mathrm{pu}, \theta_{\mathrm{ser}}=10^{\circ}\right)$ 


\section{Conclusion}

Injection power UPFC model can be incorporated in optimal power flow program. The capability of UPFC control parameters in optimal power flow applications has been demonstrated. It is clear that a UPFC can be controlled in a power system to satisfy the following objectives:

- Minimizing the generation cost which mean reduction in the total system losses.

- Enhancing the system voltage profile by reducing the load bus voltage deviations from $1.0 \mathrm{pu}$.

- Enhancing the system loadability.

\section{References:}

[1] M.Z. Elsadek ,Power Systems Voltage Stability and Power Quality, Book, Mukhtar press, Assiut, 2004.

[2] A. Edris, A.S. Mehraban, M. Rhman, L. Gyugyi, S. Arabi, and T. Reitman, "Controlling The Flow of Real and Reactive Power", IEEE Computer Application In Power, Vol, 11, pp. 20-25, January 1998.

[3] F.D Galiana, K. Almeida, M. Toussaint, J. Griffin, D. Atanackovic, B.T. Ooi and D.T. McGillis, "Assessment and Control of The Impact of FACTS Devices on Power System Performance", IEEE Transaction on Power Systems, Vol, 11 No. 4, pp. 1931-1936, November 1996.

[4] Naihu Li, Yan $\mathrm{Xu}$, and Heng Chen, "FACTS-Based Power Flow Control in Interconnected Power Systems", IEEE Transaction on Power Systems, Vol, 15 No. 1, pp. 257-262, February 2000.

[5] S Kannan, Shesha Jayaram, and M. M. A. Salama, "Real and Reactive Power Coordination for a Unified Power Flow Controller", IEEE Transaction on Power Systems, Vol. 19, No. 3, pp. 1454-1461, August 2004.

[6] Sergio Bruno, and Massimo La Scala, " Unified Power Flow Controllers for Security-Constrained Transmission Management", IEEE Transaction on Power Systems, Vol. 19, No. 1, pp. 418-426, February 2004. 
[7] M. Z. Elsadek, M. Abo-Zahhad, A. Ahmed, and H. E. Zidan, "Injection Power UPFC Model for Incorporation of Unified Power Flow Controller in Load Flow Studies", Journal of Engineering Sciences, Assiut University, Vol. 35, No. 1, pp. 203-219, January 2007.

[8] I. Papic, P. Zunko, D. Povh and M. Weinhold, " Basic Control of Unified Power Flow Controller", IEEE Transaction on Power Systems, Vol. 12, No. 4, pp. 17341739, November 1997.

[9] N. Noroozian, L. Angquist, M. Ghandhari and G. Andersson, " Use of UPFC for Optimal Power Flow Control", IEEE Transaction on Power Delivery, Vol. 12, No. 4, pp. 1629-1634, October 1997.

[10] Ray. D. Zimmerman, Carlos. E. Murillo-Sanchez, and Deqiang (David) Gan,"MATPOWER, A Matlab Power System Simulation Package", Version 3.0.0, February 14, 2005. 